\title{
Modeling of potentiation as cascaded gated processes; relevance to learning and seizure
}

Steve Adkins

Address: 25089 Larson Rd., Monroe, OR 97456, USA

Email: Steve Adkins - steviema@gmail.com

from Seventeenth Annual Computational Neuroscience Meeting: CNS*2008

Portland, OR, USA. 19-24 July 2008

Published: II July 2008

BMC Neuroscience 2008, 9(Suppl I):P65 doi: I0.1 I86/I47I-2202-9-SI-P65

This abstract is available from: http://www.biomedcentral.com/I47I-2202/9/SI/P65

(c) 2008 Adkins; licensee BioMed Central Ltd.

The neuron has elemental functionalities such as voltagegated pores and allosterically-gated enzymes. Such functionalities are cascaded in the neuron resulting in complex functionalities. Such a functionality is potentiation. Potentiation is characterized by an excitation frequency/ excitatory-postsynaptic-potential (EPSP) slope relationship. The basis of potentiation is thought to be the same as that of brain seizure and learning. I have reduced these gated elemental functionalities with the "Halfgate" device (fig 1). The behavior of the Halfgate is determined by several inputs. There is one output. The Halfgate-Set is a combination of sensors providing inputs to the Halfgate, an

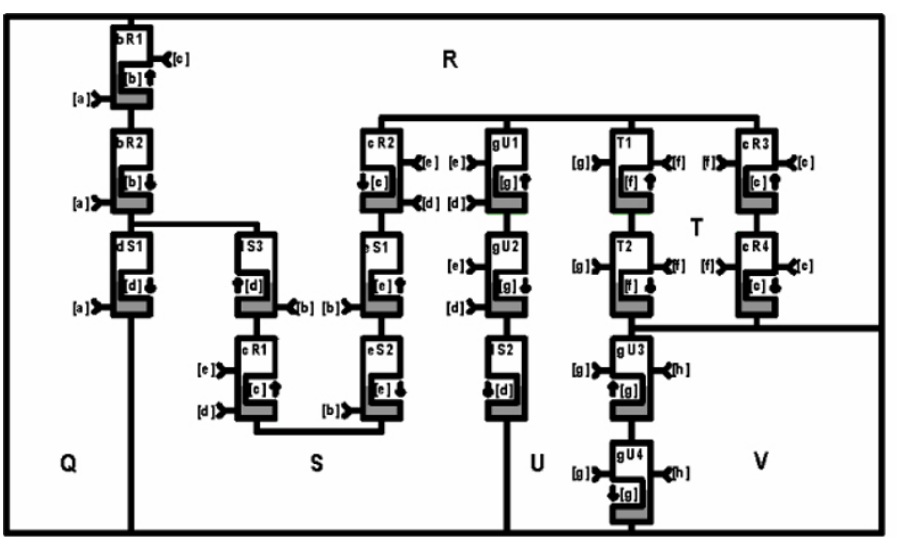

actuator receiving an output from the Halfgate and the Halfgate. The actuator modifies a single material in a single location. The "Den", which models biological potentiation, is composed of Halfgate-Sets mimicking concentration gated pores (See Fig 1). Long-term and short-term memories are embodied in the concentrations of solutes. The Den model exhibits frequency/slope behavior like that seen experimentally. In learning simulations, employing a monolayer of Den-based neurons, challenge-induced misfiring of incidental neurons was scored. Long-term memory was demonstrated: misfiring decreased regarding each successive session-start. Short-

Figure I

Schematic. Potentiation is modeled with Halfgate-Sets (rectangles with indentions), chambers (Q-V) and solutes (a-f). Specific solute concentrations (input symbols) influence Halfgates and corresponding actuators change the concentrations of a solute (indention). Graph. Concentration [a] in Q chamber (thin line) represents a high frequency input to neuron. [b] in R (heavy black line) shows an increasing slope emulating EPSP. [c] in R (light gray line) embodies memory. [c] in R controls the slope of [b] in R.

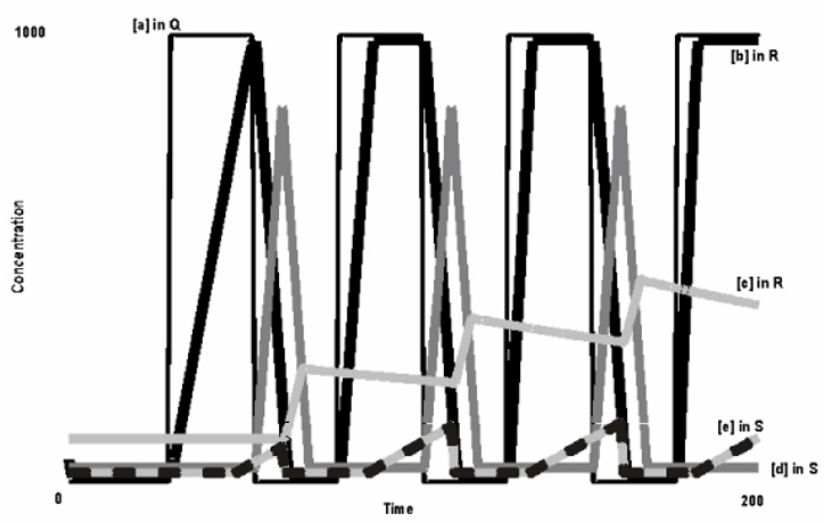


term memory was demonstrated: within a session misfiring was reduced. First session misfiring at start 50\%, end $<1 \%$; second session start 3.2\%, end $<0.1 \%$; third session start $1.8 \%$, end $<0.01 \%$. Simulating recruitment in seizure initiation, specific high frequency patterns of excitation caused $>0.1 \%$ of neurons to fire continuously. Model neurons containing subunits other than the Den are described. Models of experience-modified potentiation, and environmentally and electrically-modified seizure induction are detailed. Details are given of how microcontrollers can be used to produce task-general model brains composed of randomly interconnected neurons, which are comprised solely of cascaded gated pores.

Publish with Bio Med Central and every scientist can read your work free of charge

"BioMed Central will be the most significant development for disseminating the results of biomedical research in our lifetime. " Sir Paul Nurse, Cancer Research UK

Your research papers will be:

- available free of charge to the entire biomedical community

- peer reviewed and published immediately upon acceptance

- cited in PubMed and archived on PubMed Central

- yours - you keep the copyright

Submit your manuscript here:

http://www.biomedcentral.com/info/publishing_adv.asp 